\title{
Orta Gelir Tuzağında Türkiye: 2023 ${ }^{1}$
}

Çağla ERKOÇ, Department of Economics, Faculty of Economics and Administrative Sciences, Dokuz Eylul University, Turkey; e-mail: caglaerkocdeu@gmail.com

\section{Turkey in the Middle-Income Trap: $\mathbf{2 0 2 3}^{2}$}

\begin{abstract}
The aim of this study is to search the ways for Turkey to overcome the middle-income trap. The main problem of developing countries is that growth rate gets stationary after a certain level. Some measures can be taken to prevent the economy from remaining stagnant. This study focuses on the causes of the middle-income trap and the ways to overcome this trap. Besides, a comparison between Turkey and other developing countries is made with the help of descriptive analysis.

Keywords : Middle Income Trap, Turkey, Economic Development.

JEL Classification Codes : $\quad$ O10, O30, O50.

\section{Öz}

Bu çalışmanın amacı, Türkiye'nin orta gelir tuzağından kurtulmasının yollarını aramaktır. Gelişmekte olan ülkelerin genel sorunu, büyüme oranının belirli bir seviyeden sonra durağanlaşmasıdır. $\mathrm{Bu}$ durağanlaşmanın kalıcı olmaması için bir takım önlemler alınabilir. $\mathrm{Bu}$ çalı̧̧mada orta gelir tuzağının nedenleri ve bu tuzaktan kurtulma yöntemleri üzerinde durulmuştur. Ayrıca betimsel analiz yardımıyla Türkiye'nin gelişmekte olan ülkeler ile karşılaştırılması yapılmıştır.

Anahtar Sözcükler $\quad$ : Orta Gelir Tuzağı, Türkiye, Ekonomik Kalkınma.

I Bu makale, Dokuz Eylül Üniversitesi Íktisadi ve İdari Bilimler Fakültesi İktisat Bölümü tarafindan düzenlenen "Prof.Dr. Mehmet Sadık ACAR Bilimsel Araştırma ve Lisansüstü Tez Yarışması-2015”te üçüncülük ödülüne layık görülmüştür.

2 This paper had won the "Third Place" in "Prof.Dr. Mehmet Sadik ACAR Scientific Research and Thesis Competition-2015" organized by Dokuz Eylul University, Faculty of Economics and Administrative Sciences, Department of Economics.
\end{abstract}




\section{Giriş}

Dünya Bankası, günümüz ekonomilerini gelişmişlik düzeylerine göre 5 gruba ayırmaktadır. Yapılan bu sınıflandırmanın ölçütü ise ülkelerin kişi başına düşen gelir düzeyidir. Dünya Bankası tarafından yapılan hesaplar çerçevesinde, 2015 yılı için kişi başına y1llık ortalama geliri, 1.045 dolardan az olan ülkeler düşük gelirli; 1.045 dolar - 12.745 dolar aralığında olan ülkeler orta gelirli; 1.045 dolar - 4.125 dolar aralığında olanlar düşük orta gelirli; 4.125 dolar - 12.746 dolar aralığında olanlar yüksek orta gelirli ve 12.746 dolardan daha fazla olan ülkeler yüksek gelirli ülkeler olarak sınıflandırılmaktadır (Dünya Bankası, 2015). Bu bağlamda Türkiye, yüksek orta gelirli ülkeler kategorisinde yer almaktadır.

Zenginleşen ülkelerin büyüme oranlarının yavaşlama eğilimi göstermesi çok da şaşırılmayacak bir durumdur. Ülkelerin büyüme verileri değerlendirildiğinde, 50 yıldan fazla süre önce orta gelir düzeyine ulaşan ülkelerin ekonomilerinin, durgunluk eğilimi içine girdiği gözlemlenmektedir. Bu durgunluk nedeniyle orta gelir düzeyinde olan ülkeler, yüksek gelir düzeyine geçiş yapamamaktadır. Bir ekonomide kişi başına gelir düzeyinin belirli bir aşamadan öteye geçememesi durumu orta gelir tuzağı olarak adlandırılmaktadır.

Tablo: 1

Ülkelerin Orta Gelir Düzeyinde Kalma Süreleri

\begin{tabular}{|c|c|c|c|}
\hline Ekonomi & $\begin{array}{c}\text { 2010 KBGSYH } \\
\text { (SGP ile) (Dolar) }\end{array}$ & $\begin{array}{c}\text { Alt Orta Gelirli Olarak } \\
\text { Geçen Yıl Sayısı }\end{array}$ & $\begin{array}{c}\text { Yüksek Orta Gelirli Olarak } \\
\text { Geçen Yıl Sayısı }\end{array}$ \\
\hline Çin & 8.019 & 17 & 2 \\
\hline Tayland & 9.143 & 28 & 5 \\
\hline Bulgaristan & 8.497 & 53 & 10 \\
\hline Macaristan & 9.000 & 51 & 11 \\
\hline Polonya & 10.731 & 50 & 6 \\
\hline Türkiye & 8.123 & 51 & 8 \\
\hline Meksika & 7.763 & 53 & \\
\hline
\end{tabular}

Kaynak: Felipe, 2012.

Tablo 1'de görüldüğü gibi, düşük orta gelir düzeyinde kalma süresi Çin Halk Cumhuriyeti'nde 17 y1l iken; Türkiye için bu süre 51 senedir. Türkiye düşük orta gelir düzeyine 1955 yılında ulaşmasına rağmen yüksek orta gelir düzeyine 2005 yılında geçiş yapabilmiştir. Orta gelir bandında yaşadığı 50 sene ile Türkiye, bu düzeyde en çok süre alan ülkelerden biridir. 


\section{Türkiye Tuzağa Düştü Mü?}

Henüz 2000'li yılların başında patlak veren krizlerin ardından uygulanmaya başlanan Güçlü Ekonomiye Geçiş Programı ile Türkiye, hızlı bir büyüme performansı göstermiştir ${ }^{3}$. Türkiye İstatistik Kurumu (TÜİK) verilerine göre, Türkiye'nin Gayri Safi Yurt İçi Hasıla (GSYH)'sı \% 7 civarı büyümüştür. 2008 yılında Mortgage balonunun patlamasıyla ortaya çıkan küresel finans krizi, Türkiye ekonomisinin ciddi miktarda küçülmesine sebep olmuştur. Gelişmiş ülkelerin merkez bankalarının uyguladıkları politikalar sayesinde Türkiye, 2010 yılında yüksek büyüme oranını yakalamış; fakat 2012 yılında büyüme yeniden yavaşlamıştır. Ayrıca son 10 yılda Türkiye'de özel kesim tasarruflarının GSYH'ye oranının ciddi biçimde azalması sonucunda yatırımların finansmanında dış tasarrufların payı ciddi biçimde artmış; ekonominin yapısı özellikle ara malı ve enerji ithalatına bağımlı hale gelmiştir (Koçak ve Bulut, 2014: 3). Bunun sonucunda Türkiye ekonomisi yüksek cari işlemler hesabı açıklarıyla karşı karşıya kalmıştır. Ayrıca imalat sektöründe en çok katma değer yaratan ülkeler arasında bulunan Türkiye, 2010 yılında liste dışı kalmıştır. Beşeri sermayenin geliştirilmesi ve teknolojik ilerleme konularında da Türkiye'nin çok başarılı olduğu söylenememektedir.

Tablo: 2

Türkiye ile ABD Verilerinin Karşılaştırılması

\begin{tabular}{|c|c|c|c|}
\hline Yıllar & Türkiye KBGSYH (Dolar) & ABD KBGSYH (Dolar) & Türkiye/ABD (\%) \\
\hline $\mathbf{2 0 0 0}$ & 4.147 & 35.252 & 11,76 \\
\hline $\mathbf{2 0 0 1}$ & 3.002 & 36.065 & 8,32 \\
\hline $\mathbf{2 0 0 2}$ & 3.519 & 36.950 & 1,52 \\
\hline $\mathbf{2 0 0 3}$ & 4.535 & 38.325 & 14,83 \\
\hline $\mathbf{2 0 0 4}$ & 5.791 & 40.401 & 16,51 \\
\hline $\mathbf{2 0 0 5}$ & 7.040 & 42.629 & 17,04 \\
\hline $\mathbf{2 0 0 6}$ & 7.626 & 44.750 & 19,90 \\
\hline $\mathbf{2 0 0 7}$ & 9.245 & 46.467 & 21,90 \\
\hline $\mathbf{2 0 0 8}$ & 10.272 & 46.901 & 18,76 \\
\hline $\mathbf{2 0 0 9}$ & 8.528 & 45.461 & 21,40 \\
\hline $\mathbf{2 0 1 0}$ & 10.017 & 46.811 & 21,44 \\
\hline $\mathbf{2 0 1 1}$ & 10.363 & 48.328 & 21,00 \\
\hline $\mathbf{2 0 1 2}$ & 10.457 & 49.802 & \\
\hline
\end{tabular}

Kaynak: Ĕgilmez, 2012.

3 Ayrıntılı bilgi için bakınız: Türkiye Cumhuriyet Merkez Bankası (TCMB), $<$ http://www.tcmb.gov.tr/wps/wcm/connect/fc5a4ala-63d9-4de3-bb8bd56a61409df6/program+(1).pdf?MOD=AJPERES\&CACHEID=fc5a4ala-63d9-4de3-bb8b-d56a61409df6>. 
Eğilmez (2012) çalışmasına göre, Uluslararası Para Fonu (IMF) Dünya Ekonomik Görünümü verileri dikkate alındığında, 2006-2010 yılları arasında Türkiye kişi başına GSYH'sinin Amerika Birleşik Devletleri (ABD) kişi başına GSYH'sine oranı yüzde 20 bandında sıkışıp kalmıştır. Türkiye'nin bu görünümü, henüz düşmese bile, orta gelir tuzağının etrafında dolaştığının sinyallerini vermektedir. Tablo 2 bu konuya ilişkindir.

\section{Türkiye Orta Gelir Tuzağından Nasıl Kaçabilir?}

Dünya Bankası Türkiye Direktörü Martin Raiser, orta gelir tuzağından çıkabilen ülkelerin birkaç tane ile sınırlı kaldığını belirtmiştir (Raiser, 2015). Gerçekten de deneyimler, orta gelir tuzağından çıkışın hiç de kolay olmadığını göstermektedir. Orta gelir tuzağından çıkmayı başarabilen ülkelerin deneyimleri incelendiğinde ya petrol kaynakları tespit ettiklerini ya da sıra dışı biçimde yüksek tasarruf ve yatırım oranlarına sahip oldukları görülmektedir. Bu ülkelere Japonya ve Güney Kore örnek olarak gösterilebilir (Yeldan, 2012: 29).

Ekonomik Kalkınma ve İşbirliği Örgütü (OECD) ekonomileri arasında orta eğitime katılım oranları ve milli gelirden Araştırma ve Geliştirmeye (Ar-Ge) ayrılan pay açısından en son sırada yer alan kurumsal yapısıyla, bir türlü rayına oturtulamayan eğitim sistemiyle Türkiye, 2023 yilına yüksek gelirli bir ülke olarak girebilecek midir?

Türkiye'nin orta gelir tuzağından çıkabilmesi için ilk olarak eğitim sisteminde köklü değişikliklere gitmesi gerekmektedir. Çünkü yüksek gelir düzeyine ulaşmak için üretken bir ekonomiye geçmek gerekmektedir. Üretken bir ekonominin olmazsa olmazı ise nitelikli iş gücüdür.

OECD ülkelerinin eğitim bütçelerinin GSYH'ye oranı \%6 iken Türkiye'de bu oran \%4,23'tür. Türkiye'nin Milli Eğitim Bakanlığg (MEB)'na ayırdığ1 80 milyar Türk Lirası (TL) bütçenin \%80'inin personel harcamalarına ayrılması, düşük nitelikli eğitim tuzağı içerisinde olduğumuzu göstermektedir.

Yüksek tasarruf ve yatırım oranları, gelişmekte olan ülkelerin itici gücü olarak ifade edilebilir. Gelişmekte olan bir ülke, kullanılmayan kaynakları harekete geçirerek gelişmiş ülkelerden aldığı borçlarla öngörülen kalkınma hızını gerçekleştiremiyorsa, iç tasarrufa ağırlık vermek ve bunun boyutlarını arttıracak önlemler almak zorundadır. Çünkü düşük olan gelir düzeyinde yurt içi tasarruflar, kalkınma hızının gerçekleşmesi için gerekli yatırımları çoğunlukla tam olarak finanse edemez. Bir başka ifadeyle, gelişmekte olan ekonomilerde harcama eğilimi 1 'den büyüktür. Bu ülkelerde kalkınmanın başlatılması isteniyorsa belli bir tasarruf değerine ulaşmak gerekmektedir (Yereli, 1997: 72). Bu 
nedenledir ki Türkiye yüksek gelir düzeyine ulaşmayı istiyorsa etkili tasarruf ve yatırım politikaları üretmelidir.

Gelişmekte olan ülkeler için değinilmesi gereken belki de en önemli konu ise teknolojidir. Teknoloji bilgi toplumuna geçişteki en etkili araçtır. Teknoloji ve Ar-Ge, üretken bir ekonominin yapıtaşıdır. Teknolojinin gelişmesi dışa bağımlılığı en aza indirmektedir. Teknoloji sayesinde üretimden, nitelikli iş gücünden, yatırımlardan optimal şekilde faydalanılabilmektedir. Ayrıca ileri teknoloji, ihracat gelirlerinin de artmasını sağlayacaktır. Ancak Türkiye'de Ar-Ge harcamalarının milli gelire oranı \%1'in altında kalmaktadır. Yüksek gelir grubundaki gelişmiş ülkelerde ise bu oran \%1,5-3,5 arasında değişmektedir.

Ayrıca devlet, Ar-Ge çalışmalarının önünde en büyük engel olan rant yaratmaktan özenle kaçınmalıdır. Şurası unutulmamalıdır ki, üretim yetersizliğinin sorumlusu rekabet içindeki az gelişmiş ülkeler değil; tekelci konumda Ar-Ge malları ihraç eden gelişmiş ülkelerdir. Az gelişmiş ülkeler, gelişmiş ülkelerin talep ettikleri malları talebi doyuracak kadar üretmektedir. Fakat gelişmiş ülkeler hiçbir zaman az gelişmiş ülkelerin ihtiyaçlarını tatmin etmemiş ve bu yüzden mübadele hadleri hep yoksulların aleyhine gelişmiştir. Buna da yoksullaştıran büyüme denilmektedir (Acar, 2000: 101).

Türkiye orta gelir tuzağından çıkmak için teknolojide atılım yapmalı; yatırımları ve tasarrufları artırmalıdır. Eğitimin iyileştirilmesi ve yaygınlaştırılması yanında kadınların işgücüne katılımı da artırılmalıdır (TÜRKONFED, 2012: 119). Ülkemizde kadınların işgücüne katılım oranı \%30 civarındadır. Gelişmiş ülkelerde bu oranların \%50'nin üzerine çıktığı görülmektedir.

\section{Sonuç}

Türkiye gelişmiş ülkeler arasına girebilmek için önemli adımlar atmaktadır. Geçmişten günümüze pek çok proje hayata geçirilmiş olup pek çoğu da yapım aşamasındadır. Ancak atılan adımların yavaş olması Türkiye'yi istenilen seviyeye bir türlü getirememiştir. Buna örnek olarak Türkiye’nin en büyük entegre projesi olan Güneydoğu Anadolu Projesi (GAP) gösterilebilir.

Güneydoğu Anadolu Projesi (GAP), 37 yılda tam 27 hükümet görmesine karşın halen tamamlanabilmiş değildir. Bölgenin sosyoekonomik yapısını değiştirmeyi hedefleyen insan odaklı bir kalkınma projesi olan GAP, Türkiye'de sulanabilir arazilerin yüzde 20'sini sınırlarında bulundurmaktadır. GAP'ın en temel hedefi, bölgenin çehresini değiştirmektir. Proje tamamlandığında kişi başına düşen gelir, yüzde 200 oranında artacak; bölgenin işsizlik sorunu çözüme kavuşacaktır. Ayrıca bölgede 22 baraj, 19 hidroelektrik santrali olacak; 1,8 
milyon hektar alan sulanacak ve y1lda 27 milyar kilovat saat hidroelektrik enerji üretilecektir. GAP bölgesinden yapılan ihracatın ülke genelindeki payı iki kat artarak yüzde 4,4'e ulaşmıştır. Böylece bölgesel gelir farklılıkları bir nebze de olsa azalmaya başlamıştır.

Büyümenin ve kişi başına düşen gelir artışının nispeten yüksek düzeyde devam edebilmesi için toplam faktör verimliliğinin katkısının artması gerekir. Bu ise iyi işleyen ekonomik, siyasal ve hukuk kurumlarıyla, yüksek vasıflı işgücü ve teknolojik gelişmeyle mümkün olabilir.

İmalat sanayinin gelişimini hızlandırmak ve yaratılan katma değeri artırmak için uygulamaya konan yeni teşvik modelleri, iyi niyetli girişimler olmakla birlikte çok daha fazlasına ihtiyaç vardır. Sanayide çeşitlenmeyi gerçekleştirebilmek için her şeyden önce üzerinde çok konuşulan ama bir türlü gerçekleştirilemeyen sanayi envanteri çalışmasının tamamlanması gerekmektedir. Emek piyasasında gerekli esnekliği sağlamadan önce kayıt dışılık başta olmak üzere altyapı sorunlarını öncelikle çözmek yerinde olacaktır. Teknolojiyi kullanan, bilgiyi üreten, eğitimin kalitesini arttırıcı reformlar yapan Türkiye, orta gelir tuzağına mahkûm olmayacaktır.

\section{Kaynakça}

Acar, S. (2000), "Bilgi Çağı Ekonomisine Teorik Bir Yaklaşım”, Dokuz Eylül Üniversitesi İktisadi ve İdari Bilimler Fakültesi Dergisi, 15(1), 87-101.

Dünya Bankas1, (2015), Country and Lending Groups, <http://data.worldbank.org/about/countryand-lending-groups $>, 08.05 .2015$.

Eğilmez, M. (2012), Orta Gelir Tuză̆ı ve Türkiye, <http://www.mahfiegilmez.com/2012/12/ortagelir-tuzag-ve-turkiye.html>, 15.05.2015.

Felipe, J. (2012), “Tracking the Middle Income Trap What is It, Who is in It, and Why? Part 1", Asian Development Bank, No: 306,

$<$ http://www.adb.org/sites/default/files/publication/29804/economics-wp-306.pdf $>$, 15.05.2015.

Koçak, E. \& Ü. Bulut (2014), “Orta Gelir Tuzağı: Teorik Çerçeve, Ampirik Yaklaşımlar ve Türkiye Üzerine Ekonometrik Bir Uygulama", Maliye Dergisi, 167,

$<$ http://dergiler.sgb.gov.tr/calismalar/maliye_dergisi/yayinlar/md/167/167-01.pdf $>$, 15.05.2015.

Raiser, M. (2015), Kimi Tanıdığından 'Nasıl Yaptı̆̆ına' Geçiş: Türkiye ve Orta Gelir Tuzağı, $<$ http://www.worldbank.org/tr/news/opinion/2015/02/19/know-who-to-know-how-inturkey>, 15.05.2015.

Türk Girişim ve İş Dünyası Konfederasyonu (TÜRKONFED) (2012), Orta Gelir Tuză̆ı 'ndan Çıkış: Hangi Türkiye?, Cilt: 1: Makro/Bölgesel/Sektörel, $<$ http://turkonfed.org/Files/ContentFile/ogt-1sektorel_analiz.pdf $>$, 15.05.2015. 
Türkiye Cumhuriyet Merkez Bankası (TCMB) (2015), Türkiye’nin Güçlü Ekonomiye Geçiş Programl, <http://www.tcmb.gov.tr/wps/wcm/connect/fc5a4a1a-63d9-4de3-bb8bd56a61409df6/program+(1).pdf?MOD=AJPERES\&CACHEID=fc5a4a1a-63d9-4de3bb8b-d56a61409df6>, 15.05.2015.

Yeldan, E. (2012), “Türkiye Orta Gelir Tuzağına Yaklaşırken”, İktisat ve

Toplum, 2(21-22), <http://www.iktisatvetoplum.com/wp-content/uploads/erinc-yeldanturkiye-orta-gelir-tuzagina-yaklasirken-s21-22.pdf>, 15.05.2015.

Yereli, A.B. (1997), "Tasarruf Politikalarının Oluşumunda Vergi Sisteminin Rolü”, Maliye Yazıları, Nisan-Haziran, (55), 64-89, <http://ahmetburcinyereli.com/TPOVS.pdf>, 15.05.2015. 
Erkoç, Ç. (2015), “Orta Gelir Tuzağında Türkiye: 2023”, Sosyoekonomi, Vol. 23(26), 187-194. 